scopic observations of these objects was shown by Smith (ESTEC) who presented the first medium-energy spectrum of the supernova remnant $\mathrm{W} 49 \mathrm{~B}$. The spectrum is dominated by a remarkably strong iron line with equivalent width $2 \mathrm{keV}$ which may imply non-equilibrium ionization conditions within the X-ray plasma.

By contrast with the attention given to galactic X-ray sources, extragalactic astronomy formed a smaller part of the programme, partly because the problems encountered with the imaging detectors have meant extensive rescheduling of observations but also because of the need to build up a good understanding of the background level in the medium-energy experiment before analysing data from weak extragalactic sources. Nevertheless, interesting imaging observations of $3 \mathrm{C120}$ (Maraschi, University of Milan), BL Lac objects (Maccagni, University of Milan) and flat-spectrum radio sources (Biermann, Max Planck Institute, Bonn) were presented, while Pounds (University of Leicester) showed the first X-ray spectra of active galaxies obtained with the medium-energy experiment and Branduardi-Raymont (Mullard Space Science Laboratory), the first EXOSAT images of clusters of galaxies.

The early part of the EXOSAT mission has clearly been a success. The range of topics covered at Florence underlines the relevance of X-ray astronomy to many areas of astrophysics, while the enthusiastic participation at this meeting surely points to the rapid growth of this field in Europe.

Mike Watson is in the X-ray Astronomy Group at the University of Leicester, University Road, Leicester LEI 7RH.

\title{
Palaeohydrology
}

\section{Clues to past climate in river sediment}

\section{from Peter D. Moore}

IT is estimated that $40,000 \mathrm{~km}^{3}$ of water, carrying perhaps $15,000-20,000$ million tonnes of suspended material, run off the Earth's continents each year ${ }^{1}$. Global figures fail to indicate, however, the very high level of variation found under a range of local conditions. Sediment yield varies with the ease with which underlying geological materials are eroded, with topographical relief, which controls the energy of moving waters, with climate, which influences the total amount and temporal distribution of water movements and with the vegetation, which varies in its capacity to stabilize a substrate. So palaeoenvironmentalists have often looked to river alluvium as a source of information on changing conditions in the past ${ }^{2-5}$.

Sedimentation rates and the textural quality of sediments vary with conditions in the catchment, but it is difficult to identify the cause of change because of the complex interactions of many factors within the environment. Probably the most influential factor subject to short-term variation is the structure of vegetation, which is obviously very sensitive to human land use. Sundborg', for example, quotes data from Tanzania where, in areas of ungrazed scrub vegetation on a $3.5^{\circ}$ gradient, only 0.4 per cent of the total rainfall is lost by runoff and erosion is effectively zero. If this vegetation is replaced by grass, there is still no erosion but runoff rises to 1.9 per cent of incident rain. With arable agriculture, in the form of maize, however, 26 per cent of the rain is lost as surface runoff, carrying with it 78 tonnes of sediment per hectare of catchment; and in fallow arable, 50 per cent of the rain is lost and 146 tonnes of sediment eroded per hectare. Such figures are informative if land use, and therefore vegetation, is the only variable under consideration.

Variation in climate will have a further pronounced effect on runoff and sediment yield, as has been shown by the recent work of Finley and Gustavson in Texas ${ }^{6}$. They have been particularly interested in the influence of storms. In a study area where mean annual precipitation is about $400-500 \mathrm{~mm} \mathrm{yr}^{-1}$, a single thunderstorm in May 1978 brought $71 \mathrm{~mm}$ of rain in three hours, with a maximum intensity of $64 \mathrm{~mm}$ $\mathrm{h}^{-1}$ over a half-hour period. The resulting erosion led to a downcutting of the sandy soils at one point by $62 \mathrm{~mm}$ and the material was redeposited further down the valleys in the form of sand and gravel bars and fans. From exposed sections of similar alluvium in canyon walls it was possible to estimate an overall deposition rate of $3 \mathrm{~m}$ in $2,100-2,600 \mathrm{yr}$, but clearly deposition had not been even. A gravel lens of $10 \mathrm{~cm}$ thickness found within the sequence could easily have been deposited during a single storm.

Observations of this type serve as cautionary tales for geoarchaeologists attempting to interpret a sequence of alluvial sediments. A recent example is the work of Butzer, Miralles and Manteu ${ }^{7}$ at the site of Alzira, near Valencia in Spain. In the eleventh-century, the site was an Islamic city which was almost completely surrounded by a meander of the Rio Júcar river, which has now been cut off and remains as an infilled oxbow lake. The basal layers of the excavation, at a depth of $5 \mathrm{~m}$, are clayey silts, which contain very little sand and are archaeologically sterile. Above $450 \mathrm{~cm}$, the sand content increases grad- ually to about 25 per cent at $270 \mathrm{~cm}$, above which there is a further abrupt increase, together with evidence of dwelling construction. Yet more sand builds up above about $150 \mathrm{~cm}$ depth.

To assist in the interpretation of the deposits, modern samples were collected from a variety of local sedimentary environments with known depositional characteristics and were compared with the fossil samples in terms of particle size and sorting parameters. In this way, the sedimentary history of the site has been reconstructed.

At the base, conditions were of a lowenergy type, with steady deposition and no evidence of erratic floods. Regular flooding occurred during the mid-eleventh century, coincident with the building of the city walls, culminating in high-energy floods in the late eleventh century. Sudden changes in the sand content above about $270 \mathrm{~cm}$ are due to further construction at the site. The dwelling had to be abandoned eventually, however, because of catastrophic floods in the sixteenth and seventeenth centuries, leading to the deposition of the sand-rich sediments at a depth of $100-150 \mathrm{~cm}$.

The story, therefore, is one of stable lowenergy conditions being replaced in the eleventh century by increasingly severe floods which probably continued into the twelfth and thirteenth centuries. Subsequently, there is evidence for infrequent, but catastrophic, flooding. The question remains, however, whether the changing hydrological circumstances resulted from alterations in human land use or from anomalies of climate.

The fact that, after the eleventh-century floods, conditions never fully reverted to the stability of the tenth century, has led Butzer and his co-workers to suggest that a permanent change in the nature of the catchment had been brought about, most probably because of deforestation during the Islamic occupation of the area. The more recent incidence of irregular catastrophic floods is accounted for in terms of climatic anomalies whose effects have been amplified by the unstable state of the floodplain, which was the result of both the earlier deforestation, itself, and consequent aggradation in the upper part of the valley. $\square$

Peter D. Moore is Senior Lecturer in the Department of Plant Sciences, University of London King's College, 68 Half Moon Lane, London SE24 9JF.

1. Sundborg, A. Nature and Resources (UNESCO) 19(2), 10 (1983).

2. Vita-Finzi, C. The Mediterranean Valleys (Cambridge University Press, 1969).

3. Dennell, $R . W$. in Desertification and Development (eds Spooner, B. \& Mani, H.S.) 171 (Academic, London, 1982).

4. Moore, P.D. Quat. Stud. Poland 4, 97 (1983).

5. Gregory, K.J. Background to Paleohydrology (Wiley, Chichester, 1983)

6. Finley, R.J. \& Gustavson, T.C. Earth Surf. Processes and Landforms 8, 63 (1983).

7. Butzer, K.W., Miralles, I. \& Mateu, J.F. J. archaeol. Sci. 10,333 (1983). 